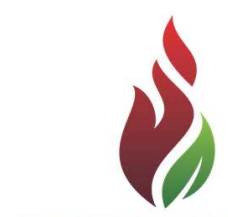

SUSTENERE

Publishing Corporation

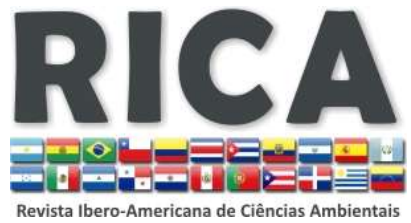

Journals Homepage:

www.sustenere.co/journals

\section{ANÁLISE QUALITATIVA E QUANTITATIVA DA PRODUÇÃO DE BIOGÁS EM ATERRO SANITÁRIO}

\section{RESUMO}

A geração de energia elétrica a partir do biogás de aterros sanitários é uma alternativa ambiental importante. Entretanto, esta prática depende muito do melhor entendimento da produção do biogás. Os resíduos sólidos urbanos destinados de maneira adequada nos aterros sanitários, por meio da ação dos micro-organismos e fatores ambientais, os resíduos orgânicos presentes nos resíduos sólidos urbanos irão se biodegradar, produzindo o biogás, que é um gás formado essencialmente pelo metano. O presente estudo tem como objetivo avaliar qualitativamente quantitativamente a produção de biogás em aterro sanitário. $O$ estudo foi realizado no Aterro Sanitário Caieiras, localizado no estado de São Paulo, Brasil. O biogás foi monitorado por meio de medições através de um analisador portátil de biogás nos drenos verticais (poços) de captação de gás do aterro sanitário. A partir dos resultados obtidos pode-se dizer que a vazão e composição de biogás no aterro sanitário dependem muito do sistema operacional e os procedimentos para implantação e adaptação dos drenos verticais. Este estudo contribui para estimar a produção de biogás e, principalmente determinar o teor de metano do biogás, gás de grande interesse econômico e ambiental e potencialmente viável para valorização ambiental e energética do gás metano em aterro sanitário.

PALAVRAS-CHAVES: Resíduo Sólido; Aterro Sanitário; Biogás; Metano.

\section{QUALITATIVE AND QUANTITATIVE ANALYSIS OF PRODUCTION OF BIOGAS IN SANITARY LANDFILL}

\section{ABSTRACT}

The generation of electricity from landfill gas is an important alternative. However, this practice relies heavily on the better understanding of the biogas production. Municipal solid waste properly in landfills, through the action of micro-organisms and environmental factors, the organic residues present in municipal solid waste will biodegrade, producing biogas, which is a gas consisting essentially of methane. The present study aims to qualitatively and quantitatively evaluate the production of biogas in the landfill. The study was conducted in Caieiras Landfill, located in the state of São Paulo, Brazil. The biogas was monitored by measurements using a portable analyzer for biogas in vertical wells (wells) to capture the landfill gas. From the results obtained it can be said that the flow and composition of biogas at landfill rely heavily on the operating system and the procedures for implementation and adaptation of vertical drains. This study contributes to estimate biogas production and mainly determine the methane content of biogas, of great economic and environmental interest gas and potentially viable for environmental and energy recovery of landfill methane gas.

KEYWORDS: Solid Waste; Landfill; Biogas; Methane.
Revista Ibero-Americana de

Ciências Ambientais, Aquidabã, v.6, n.1, Dez2014, Jan, Fev, Mar, Abr, Mai 2015.

ISSN 2179-6858

SECTION: Articles

TOPIC: Saneamento e Tratamento de Resíduos

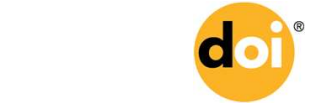

DOI: 10.6008/SPC2179-6858.2015.001.0022

Giovano Candiani

Universidade Federal de São Paulo, Brasil http://lattes.cnpq.br/9950995765229751 giovanocandiani@gmail.com

Diego Castellano Torres

Faculdades Oswaldo Cruz, Brasil http://lattes.cnpq.br/2708234873550204 diegocastellano90@gmail.com

Received: 09/11/2014

Approved: 09/04/2015

Reviewed anonymously in the process of blind peer

Referencingthis:

CANDIANI, G.; TORRES, D. C.. Análise qualitativa e quantitativa da produção de biogás em aterro sanitário. Revista Ibero-Americana de Ciências Ambientais,

Aquidabã, v.6, n.1, p.285-292, 2015. DOI: http://dx.doi.org/10.6008/SPC21796858.2015 .001 .0022 


\section{INTRODUÇÃO}

O Aquecimento Global é associado ao aumento das emissões de gases de efeito estufa gerado pelas ações antrópicas, elevando a temperatura do Planeta. Os aterros sanitários contribuem com a emissão de significativas quantidades de dióxido de carbono $\left(\mathrm{CO}_{2}\right)$ e gás metano $\left(\mathrm{CH}_{4}\right)$, gerados com a biodegradação dos resíduos sólidos urbanos. $\mathrm{O}$ aterro sanitário no Brasil, ainda é a técnica mais utilizada de disposição final de resíduos sólidos urbanos, porém com a aprovação da Política Nacional de Resíduos Sólidos - PNRS, lei n. 12.305/2010 existe a diretriz de se reduzir gradativamente os aterros sanitários, e ser encaminhado para estes somente rejeitos e não mais resíduos. A ideia é que os resíduos devem ser reaproveitados ao máximo. Uma indicação forte da PNRS é em relação ao aproveitamento do biogás do aterro sanitário.

O metano contido no biogás após sua captação pelos drenos verticais (poços) no aterro sanitário pode ser queimado em motores, gerando energia elétrica. Segundo a Associação Brasileira de Empresas de Limpeza Pública e Resíduos Especiais - ABRELPE (2013), utilizando a geração de resíduos sólidos urbanos no Brasil e o modelo matemático de geração de metano do Intergovernmental Panel on Climate Change - IPCC (2000), o Brasil apresenta um potencial de geração de eletricidade a partir de biogás de resíduo de cerca de $280 \mathrm{MW}$. Nesse sentido, o biogás de aterro sanitário torna-se cada vez mais importante como fonte energética, e estudos que busquem aperfeiçoar a recuperação do biogás no aterro sanitário são fundamentais. Assim, o objetivodeste trabalho é avaliar qualitativamente e quantitativamente a produção de biogás em aterro sanitário, subsidiando-se estudos e planejamentos para recuperação do biogás e aproveitamento energético.

\section{MATERIAIS E MÉTODOS}

\section{Local de Estudo}

O estudo foi realizado no Aterro Sanitário Caieiras, localizado no município de Caieiras (2321'51"S e 4644'26" W) no estado de São Paulo, Brasil (Figura1). O município de Caieiras se situa na Região Metropolitana de São Paulo (RMSP), possui uma área de $95,89 \mathrm{Km}^{2}$ e população de 86.623 habitantes e está inserido em uma região de clima subtropical, tipo Cfb (segundo a classificação de Köppen), com uma precipitação média anual de 1.500 mm (IBGE, 2010). O Aterro ocupa uma área de 350 hectares (ha), sendo formado por um sistema de impermeabilização de base composto por: solo siltoso compactado $(3 \mathrm{~m})$, argila $(1 \mathrm{~m})$ compactada, geomembrana de PEAD de 2,5 mm, geotêxtil e camada drenante. Atualmente, recebe cerca de 7.000 toneladas de resíduo sólido urbano (RSU)/dia, provenientes de 17 municípios de São Paulo. No período de 2002 a 2013, o aterro já recebeu aproximadamente 22 milhões de toneladas de RSU, perfazendo um maciço sanitário de cerca de $70 \mathrm{~m}$ de altura (ESSENCIS, 2012).

Os resíduos recebidos são compactados e recobertos com uma camada de solo com espessura de $0,5 \mathrm{~m}$. O lixiviado (chorume) e o biogás produzidos são coletados e captados e 
respectivamente são armazenados em bacias de contenção e tratados em uma unidade de captação de biogás com queima em flares. O biogás captado é monitorado por um sistema de controle automático, sendo produzidos créditos de carbono e futuramente será instalada no aterro uma termelétrica para produção de energia elétrica.Esta usina termelétrica terá potência instalada de aproximadamente $30 \mathrm{MW}$. O Aterro apresenta seis fases de operação, sendo que as fases I, II e III e existe a captação de biogás, local objeto deste estudo. As fases IV e V encontram-se em operação, recebendo os resíduos sólidos urbanos e a fase VI encontra-se em obras para sua implantação (ESSENCIS, 2012).

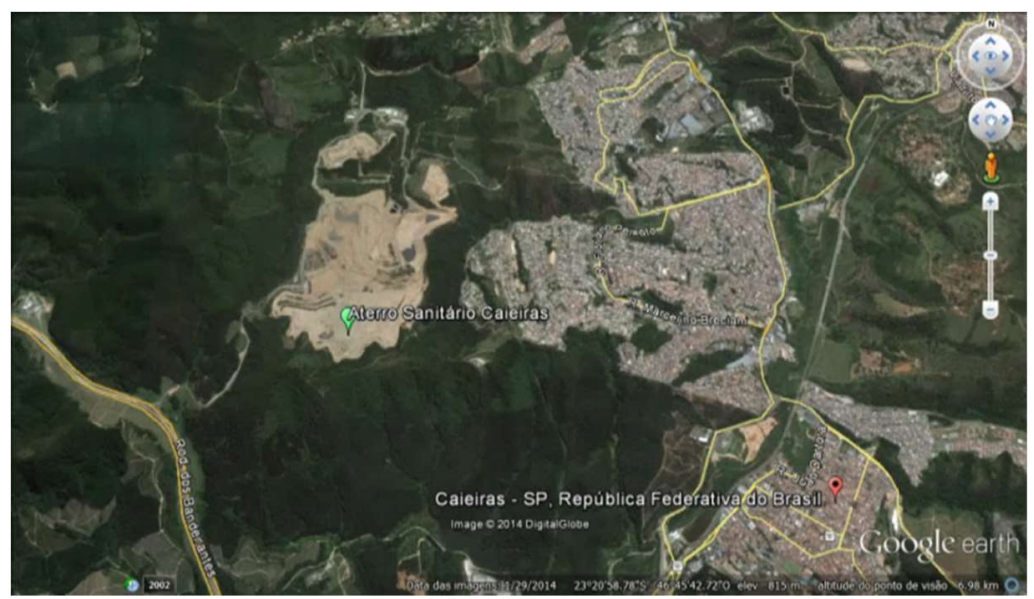

Figura 1: Aterro Sanitário Caieiras (SP).

Fonte: Google Earth (2014).

\section{Monitoramento do Biogás no Aterro Sanitário}

Para realização deste estudo foram utilizados os seguintes equipamentos: Analisador de gás portátil - Marca LANDTEC-GEM 2000 (medições de temperatura, pressão e composição do biogás - $\mathrm{CH}_{4}, \mathrm{CO}_{2}$ e $\mathrm{O}_{2}$ ) e Anemômetro - Marca LANDTEC. (medições de velocidade de fluxo do biogás), utilizadas para medir a vazão do biogás. O monitoramento do biogás no aterro sanitário foi realizado através de medições de biogás nos drenos verticais (Figura 2) do aterro, utilizando-se nas medições um analisador portátil de gás (Figura 3). Porém, este equipamento mede somente a velocidade do biogás. Para medir a vazão de biogás foi necessário fazer um procedimento adaptativo, utilização de uma peça para diminuir a seção nos drenos verticais, pois a vazão efetiva de biogás foi obtida multiplicando-se a velocidade do biogás pela seção (área) da peça. A peça adaptativapara medição da vazão nos drenos verticais foi construída utilizando-se um retalho de geomembrana de PEAD de $2 \mathrm{~mm}$ e $1 \mathrm{~m}$ de tubulação de policloreto de vinila - PVC de 1,5 polegadas. Esta peça construída se conecta ao dreno vertical adaptado, permitindo medir a velocidade do gás (Figura 3). As medições de vazão do biogás no aterro sanitário foram realizadas, de acordo com a Equação (1) Ensinas (2003):

$$
Q=(V \times A) \times \frac{273,15}{273,15+T} \times P(\text { Equação } 1)
$$

onde: 

Q: vazão de biogás $\left(\mathrm{Nm}^{3} / \mathrm{s}\right)$;
$V$ : velocidade de saída do biogás $(\mathrm{m} / \mathrm{s})$;
A: área da seção de passagem do fluido $\left(\mathrm{m}^{2}\right)$;
$T$ : temperatura de saída do biogás $\left({ }^{\circ} \mathrm{C}\right)$ e;
$P$ : pressão atmosférica (bar).

Para realização das medições do biogás, foram utilizados 9 drenos verticais, com medições semanais por um período de 6 meses. O biogás apresenta comportamento termodinâmico de um gás ideal, assim calcula-se a vazão volumétrica, corrigida para as Condições Normais de Temperatura e Pressão $\left(0^{\circ} \mathrm{C}\right.$ e 1 bar $)$ recomendadas pela Internation Union of Pure and a Applied Chemistry, de acordo com Ensinas (2003).

As medições do biogás nos drenos verticais no aterro sanitário foram realizadas da seguinte maneira: primeiramente retira-se o cabeçote de PEAD que está conectado ao dreno vertical adaptado. Para evitar a entrada de ar atmosférico pelos cabeçotes no sistema de tubulações da rede de captação de biogás, prejudicando a eficiência do sistema, foi utilizado um procedimento de vedação dos cabeçotes por meio de uma rolha de borracha confeccionada e adaptada, evitando-se essa entrada de ar; após este procedimento, foram realizadas as medições de biogás (composição, velocidade e vazão).

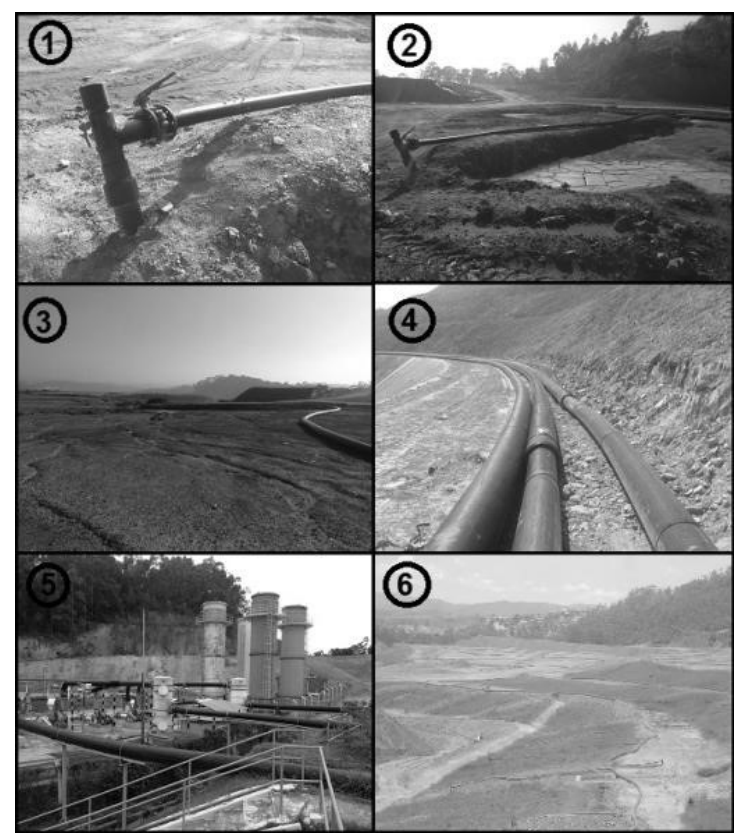

Figura 2-1 e 2: drenos verticais de biogás; 3 e 4: tubulações para captação do biogás; 5: unidade de captação do biogás; 6: rede de tubulações no aterro.

As medidas de velocidade foram realizadas com o anemômetro, sendo este instalado perpendicularmente ao fluxo de biogás, ao centro do tubo de PVC, a uma distância de aproximadamente $40 \mathrm{~cm}$ da peça de adaptação do dreno vertical para realizar as medidas; foram realizadas medidas de temperatura do biogás utilizando-se um termômetro termopar - marca LANDTEC presente no kit do analisador portátil de biogás, marca LANDTEC - GEM 2.000, introduzido na peça no mesmo ponto de medição da velocidade; antes dos monitoramentos em cada dreno vertical foi feita uma avaliação da direção e intensidade do vento, para que na saída da peça durante as medições não ficasse posicionada na direção oposta ao vento ou as medições 
expostas a ventos de maior intensidade; para a leitura da velocidade do biogás, após a montagem do equipamento foi introduzido o anemômetro no orifício da peça e desta maneira realizou-se as medições, que foram registradas no painel do analisador e em planilhas de controle; a composição do biogás $\left(\mathrm{CH}_{4}, \mathrm{CO}_{2}\right.$ e $\left.\mathrm{O}_{2}\right)$ foi realizada com o analisador portátil de gás, sendo efetuada com a conexão do equipamento ao dreno adaptado, utilizando-se a peça adaptativa, após isto foram registrados os valores da composição do biogás.

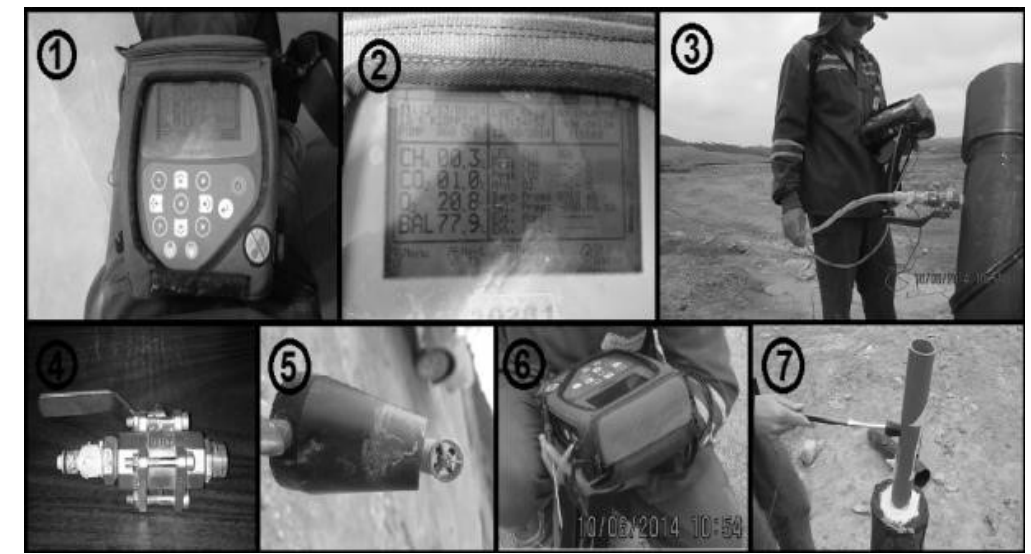

Figura 3 - 1: analisador de gás portátil (GEM 2000); 2: painel do GEM 2000; 3: procedimento de monitoramento da composição e pressão do biogás; 4 : ferramenta para monitorar nos cabeçotes; 5 : anemômetro para medir a velocidade; 6: medidor de temperatura conectado ao GEM 2000; 7: monitoramento da vazão na saída do dreno adaptado.

\section{RESULTADOS}

A vazão total de biogás considerando os drenos verticais monitorados no aterro sanitário deste estudo foi de $1.659 \mathrm{Nm}^{3} / \mathrm{h}$. A vazão total de gás metano foi de $999,9 \mathrm{Nm} 3 / \mathrm{h}$. A vazão média de biogás por dreno vertical foi de $20,5 \mathrm{Nm}^{3} / \mathrm{h}$ e a vazão média de gás metano por dreno vertical de $12,34 \mathrm{Nm}^{3} / \mathrm{h}$, conforme mostra a Tabela 1 . Os resultados obtidos neste trabalho são similares ao estudo realizado por Ensinas (2003) com o monitoramento do biogás no Aterro Sanitário Delta. Ensinas (2003) obteve os seguintes resultados: a vazão total de biogás foi de $1.649 \mathrm{Nm} 3 / \mathrm{h}$, a vazão total de gás metano foi de $930,7 \mathrm{Nm}^{3} / \mathrm{h}$, a vazão média de biogás por dreno vertical foi de $15,56 \mathrm{Nm}^{3} / \mathrm{h}$ e a vazão média de gás metano por dreno vertical foi de $8,78 \mathrm{Nm}^{3} / \mathrm{h}$.

Tabela 1: Vazões de biogás e gás metano dos drenos verticais no aterro sanitário.

\begin{tabular}{|l|c|}
\hline $\begin{array}{l}\text { Vazão total de biogás } \\
\left(\mathrm{Nm}^{3} / \mathrm{h}\right)\end{array}$ & 1.659 \\
\hline $\begin{array}{l}\text { Vazão total de gás metano } \\
(\mathrm{Nm} 3 / \mathrm{h})\end{array}$ & 999,9 \\
\hline $\begin{array}{l}\text { Vazão média de biogás por dreno } \\
\left(\mathrm{Nm}^{3} / \mathrm{h}\right)\end{array}$ & 20,5 \\
\hline Vazão média de gás metano por dreno $\left(\mathrm{Nm}^{3} / \mathrm{h}\right)$ & 12,34 \\
\hline
\end{tabular}

Nas medições de biogás nos drenos verticais no aterro sanitário, foi possível constatar grandes variações na vazão de biogás, fato já encontrado e mencionado em estudos anteriores (ENSINAS, 2003; BRITO FILHO, 2005; SILVA \& CAMPOS, 2008). Esse resultado aponta que a produção de biogás em aterro sanitário não depende exclusivamente do processo de biodegradação dos resíduos sólidos, mas aspectos construtivos de engenharia, em relação à implantação dos drenos verticais, sistemas de drenagens no aterro sanitário e procedimentos 
operacionais. Em relação aos drenos verticais monitorados no aterro sanitário, a maior vazão de biogás obtida foi de $46,49 \mathrm{Nm}^{3} / \mathrm{h}$ e a menor de $6,24 \mathrm{Nm}^{3} / \mathrm{h}$. Considerando a vazão média de biogás $\left(20,5 \mathrm{Nm}^{3} / \mathrm{h}\right)$ no aterro sanitário, estes resultados representam respectivamente, $227 \%$ acima da média do aterro sanitário e $30 \%$ abaixo da média do aterro sanitário.

A Tabela 2 mostra a vazão total de biogás e gás metano obtida por fase neste estudo. Nota-se que a fase II é a que apresenta maior contribuição em relação à produção de biogás no aterro sanitário, seguido pela fase I e fase III. Essas variações podem ser explicadas em função da idade dos resíduos depositados no aterro sanitário, ou seja, como o aterro opera em sistemas de camadas de resíduos e a entrada dos resíduos é constante e diária, estes são misturados durante a deposição no aterro, desta maneira a produção de biogás é resultado de uma mistura de resíduos com diferentes idades e etapas em termos do processo de biodegradação, condição que resulta nessas variações na produção de biogás observadas nos monitoramentos no aterro sanitário. Portanto, aspecto similar também acaba ocorrendo com a produção de metano no aterro sanitário. A Tabela 3 mostra a vazão média de biogás e gás metano obtida por fase neste estudo. É possível observa-se o mesmo cenário em relação às vazões médias de biogás e metano por fase no aterro sanitário.

Tabela 2: Vazão total de biogás e gás metano por fase no aterro sanitário.

\begin{tabular}{|l|l|}
\hline Vazão total de biogás por fase do aterro $\left(\mathrm{Nm}^{3} / \mathrm{h}\right)$ & 678,36 \\
Fase I & 716,19 \\
Fase II & 264,39 \\
Fase III & 411,19 \\
\hline Vazão total de metano por fase do aterro $\left(\mathrm{Nm}^{3} / \mathrm{h}\right)$ & 430,08 \\
Fase I & 158,61 \\
Fase II & \\
Fase III & \\
\hline
\end{tabular}

Tabela 3: Vazão média de biogás e gás metano por fase no aterro sanitário.

\begin{tabular}{|l|l|}
\hline Vazão média de biogás por fase do aterro $\left(\mathrm{Nm}^{3} / \mathrm{h}\right)$ & 25,12 \\
Fase I & 26,52 \\
Fase II & 9,79 \\
Fase III & 15,22 \\
\hline Vazão média de metano por fase do aterro $\left(\mathrm{Nm}^{3} / \mathrm{h}\right)$ & 15,92 \\
Fase I & 5,87 \\
Fase II & \\
Fase III & \\
\hline
\end{tabular}

A Tabela 4 mostra a composição média do biogás obtida nos drenos verticais monitorados no aterro sanitário. A composição do biogás foi de $58,7 \%$ de metano, $40,5 \%$ de dióxido de carbono e $0,6 \%$ de oxigênio. $O$ valor de metano obtido é similar aos valores de outros aterros sanitários, como: Aterro Bandeirantes (SP) - 59,5\%, Aterro São João (SP) - 60,9\% e Aterro Delta (SP) - 55,13\% (ENSINAS, 2003).

Tabela 4: Composição média (\%) do biogás no aterro sanitário.

\begin{tabular}{|l|l|}
\hline Componente & Teor (\%) \\
\hline Metano $\left(\mathrm{CH}_{4}\right)$ & 58,7 \\
\hline Dióxido de Carbono $\left(\mathrm{CO}_{2}\right)$ & 40,5 \\
\hline Oxigênio $\left(\mathrm{O}_{2}\right)$ & 0,6 \\
\hline
\end{tabular}


A Tabela 5 mostra a composição do biogás típica produzida a partir da decomposição dos resíduos orgânicos presentes nos resíduos sólidos nos aterros sanitários (TCHOBANOGLOUS et al., 1993). Nota-se que os valores da composição do biogás obtido no aterro, encontram-se dentro da faixa conforme a Tabela 5. O Aterro Sanitário Caieirastem aproximadamente 230 drenos verticais nas fases I, II e III, estudadas neste trabalho. Os drenos verticais são distribuídos da seguinte forma: 61 drenos na fase I, 85 drenos na fase II e 82 na fase III (ESSENCIS, 2012). Considerando a vazão média de biogás $\left(20,5 \mathrm{Nm}^{3} / \mathrm{h}\right)$ e metano $\left(12,34 \mathrm{Nm}^{3} / \mathrm{h}\right)$ por dreno vertical obtida nesse estudo e o número de drenos verticais do aterro (230), estima-se que o Aterro Sanitário Caieiras esteja produzindo cerca de $4.700 \mathrm{Nm}^{3} / \mathrm{h}$ de biogás e aproximadamente 2.840 $\mathrm{Nm}^{3} / \mathrm{h}$ de metano. Com esta produção de metano, pode-se estimar uma potencia elétrica de 8,5 MW (ENSINAS, 2003).

Nos monitoramentos de campo do biogás nos drenos verticais do aterro sanitário, foi possível constatar alguns procedimentos operacionais no aterro que pode explicar as variações da produção de biogás nos drenos verticais e, portanto, no aterro sanitário. A operação de um aterro sanitário é muito dinâmica, pois o recebimento dos resíduos é muito frequente e em curtos intervalos de tempo, isto acaba exigindo que as tubulações e redes de captação de biogás no aterro tenham que ser constantemente movimentadas, ocasionando influencia na produção e composição do biogás nos drenos verticais do aterro sanitário.

Esta operação de forma aleatória com deposição diária de resíduo em diversas partes do aterro promove a sobreposição de camadas de resíduo com idades muito diferentes, sendo o biogás resultante de uma mistura de diversas fases de biodegradação do resíduo, fato que acaba contribuindo para as variações obtidas em relação à vazão e composição de biogás no aterro sanitário.Esses resultados mostram que a vazão e composição de biogás no aterro sanitário dependem muito do sistema operacional, os procedimentos para implantação e adaptação dos drenos verticais.

Tabela 5: Composição do biogás de aterro sanitário (TCHOBANOGLOUS et al., 1993).

\begin{tabular}{|l|l|}
\hline Composição & $\%$ \\
\hline Metano & $45-60$ \\
\hline Dióxido de carbono & $40-60$ \\
\hline Nitrogênio & $2,0-5,0$ \\
\hline Oxigênio & $0,1-1,0$ \\
\hline Enxofre & $0-1,0$ \\
\hline Amônia & $0-0,2$ \\
\hline Hidrogênio & $0-0,2$ \\
\hline Monóxido de carbono & $0-0,2$ \\
\hline Gases em menor concentração & $0,01-0,6$ \\
\hline
\end{tabular}

\section{CONCLUSÕES}

A partir dos resultados obtidos neste trabalho, pode-se concluir que: as medições realizadas nos drenos verticais são eficientes para se analisar a quantidade e qualidade do biogás no aterro sanitário; pela vazão de biogás e teor de metano obtidos neste estudo pode-se dizer que o Aterro Sanitário Caieiras encontra-se em fase de produção avançada, portanto, com potencial 
energético elevado; vários fatores interferem na geração e composição do biogás, sendo possível destacar os itens: procedimentos operacionais e infraestruturas do aterro e biogás (implantação e adaptação dos drenos verticais e tubulações), que acabam influenciando o sistema de captação; estudos quali quantitativos do biogás em aterro sanitário contribuem para estimar a produção de biogás e, principalmente determinar o teor de metano do biogás, gás de grande interesse econômico e ambiental e potencialidades para valorização ambiental e energética.

\section{REFERÊNCIAS}

ABRELPE. ASSOCIAÇÃO BRASILEIRA DE LIMPEZA PÚBLICA E RESÍDUOS ESPECIAIS. Panorama dos Resíduos Sólidos no Brasil - 2013. São Paulo: ABRELPE, 2013.

BRITO FILHO, L. F.. Estudo de gases em aterros de resíduos sólidos urbanos. Dissertação (Mestrado em Ciências) - Universidade Federal do Rio de Janeiro, Rio de Janeiro, 2005.

ENSINAS, A. V.. Estudo da geração de biogás no aterro sanitário Delta em Campinas (SP).

Dissertação (Mestrado em Engenharia Mecânica) - Universidade Estadual de Campinas, Campinas, 2012.

IPCC. INTERGOVERNMENTAL PANEL ON CLIMATE CHANGE - 2000. Guidelines for National Greenhouse Inventories: Reference Manual. IPCC, 2000.

IBGE. INSTITUTO BRASILEIRO DE GEOGRAFIA E ESTATíSTICA. Rio de Janeiro: IGBE/Ministério das Cidades/Ministério do Planejamento, Orçamento e Gestão, 2010.

SILVA, T. N.; CAMPOS, L. M. S.. Avaliação da produção e qualidade do gás de aterro para energia no aterro sanitário dos Bandeirantes (SP). Revista Engenharia Sanitária Ambiental, v.13, n.1, p.88-96, 2008.

TCHOBANOGLOUS, G.; THEISEN, H.; VINIL, S.. Integrated Solid Waste Management: Engineering principles and management issues. Washington: McGraw-Hill, 1993. 